ARTÍCULO DE REVISIÓN

\title{
Artritis reumatoide de la cabeza a los pies. Hallazgos radiológicos comunes
}

\section{Rheumatoid Arthritis from head to toe. Common radiological findings}

Dulce A. Sánchez-Nava* y Juan A. Garay-Mora

Departamento de Radiología e Imagen, Instituto Nacional de Ciencias Médicas y Nutrición Salvador Zubirán, Ciudad de México, México

\section{RESUMEN}

La artritis reumatoide (AR) es una enfermedad sistémica, crónica e inflamatoria que afecta principalmente las articulaciones sinoviales. Ocurre aproximadamente en el 0.5 a $1 \%$ de la población mundial y tiene predilección por el sexo femenino. El diagnóstico requiere de una serie de criterios dentro de los cuales se encuentra el radiológico. Si bien el ultrasonido y la resonancia magnética permiten valorar el involucro articular y de tejidos blandos, la radiografía es el estudio inicial. La distribución característica de esta enfermedad (bilateral, simétrica y poliarticular) permite su diagnóstico con alta precisión. El diagnóstico temprano y el inicio del tratamiento de forma oportuna modifica el curso de la enfermedad y su pronóstico, por lo que es importante que el médico radiólogo se familiarice con los hallazgos tempranos de la misma.

Palabras clave: Artritis reumatoide. Radiografía. Articulación sinovial.

\section{ABSTRACT}

Rheumatoid arthritis (RA) is a systemic, chronic and inflammatory disease that primarily affects synovial joints. It affects approximately 0.5 to $1 \%$ of the world population and has a predilection for the female sex. The diagnosis requires a series of criteria within which the radiological one is a keystone. Although ultrasound and magnetic resonance imaging allow assessing joint and soft tissue involvement, radiography is the initial study. The characteristic distribution of this disease (bilateral, symmetric and polyarticular), allows its diagnosis with high precision. Early diagno- 
sis and proper initiation of treatment in a time help modify the natural course of the disease and its prognosis. Therefore, the radiologist must become familiar with the early findings in RA.

Key words: Rheumatoid arthritis. Radiography. Synovial joint.

\section{INTRODUCCIÓN}

La artritis reumatoide(AR) es una enfermedad inflamatoria, crónica y sistémica de etiología desconocida que afecta principalmente a las articulaciones sinoviales. Se estima que afecta a aproximadamente el $1 \%$ de la población mundial ${ }^{1}$. La incidencia anual es de 12-24.5 en hombres y de 23.9-54 en mujeres por 100,000 habitantes y el pico de incidencia es entre los 45 a 65 años $^{2}$. La enfermedad se origina de una combinación de eventos genéticos predeterminados y otros estocásticos que pueden ocurrir al azar. Los genes del complejo mayor de histocompatibilidad del antígeno leucocitario humano se encuentran involucrados en la fisiopatología de la enfermedad, aunque se han descrito algunos otros. La artritis reumatoide se caracteriza por la infiltración de células inflamatorias (linfocitos $\mathrm{T}$, linfocitos $\mathrm{B}$ y monocitos) en la membrana sinovial y por la activación de células endoteliales que generan neovascularización, lo que genera hiperplasia sinovial. Esta expansión de la membrana sinovial (pannus) invade la unión entre cartílago y hueso, generando erosiones óseas y degradación del cartílago (Fig. 1) $)^{3-6}$.

El mecanismo más probable del componente ambiental es la activación repetida de la inmunidad innata. Los pacientes con AR están propensos a tener activación inmune

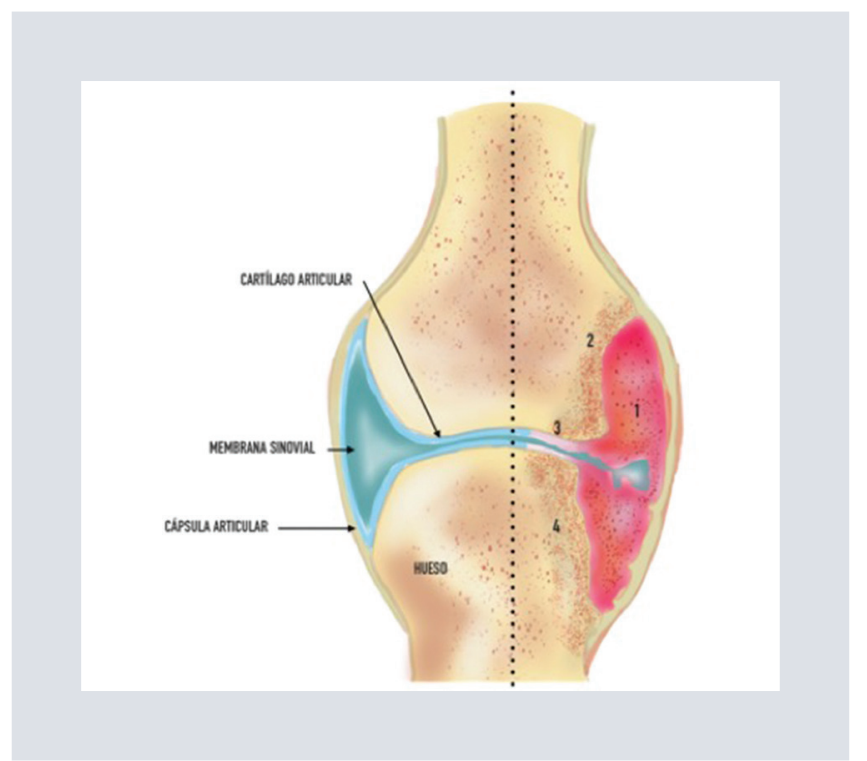

Figura 1. Fisiopatología. Representación esquemática de una articulación sinovial normal (lado izquierdo) y de una articulación afectada por artritis reumatoide (lado derecho), con los componentes principales: 1) hipertrofia sinovial con hiperemia, 2) erosiones óseas, 3) disminución del espacio articular y 4) osteopenia yuxtaarticular.

por nuevos epítopes creados por la modificación de proteínas, como la citrulinización, que resulta de estresores ambientales como el tabaco; esto lleva a la producción de anticuerpos contra proteínas citrulinadas que pueden iniciar la inflamación y el depósito de complemento en los tejidos ${ }^{3}$.

La AR típica se manifiesta de manera insidiosa con dolor, rigidez e inflamación poliarticular. Las articulaciones metacarpofalángicas, interfalángicas proximales, muñecas y metatarsofalángicas son los principales sitios 
de afección inicial. Una proporción importante de pacientes puede presentarse con una constelación de síntomas extraarticulares que pueden incluso anteceder la aparición de la artritis. Algunos de estos incluyen dolor generalizado, rigidez, síndrome de túnel del carpo bilateral, pérdida de peso, depresión y fatiga. Para identificar sujetos con la enfermedad se utilizan los criterios del Colegio Americano de Reumatología y la Liga Europea Contra el Reumatismo (ACR/EULAR) actualizados en 2010 (Tabla 1) ${ }^{4}$.

Los estudios de imagen son piedra angular para el abordaje de la AR. Las radiografías convencionales son el estudio inicial en la mayoría de los escenarios clínicos y se pueden encontrar cambios relacionados con la enfermedad en estadios iniciales. Las imágenes por resonancia magnética $(\mathrm{RM})$ y el ultrasonido confieren una sensibilidad mayor en la detección de afección a tejidos blandos, aunque su papel en el pronóstico del paciente no está totalmente determinado ${ }^{5}$. Se recomienda obtener radiografías de manos, muñecas y pies para la valoración inicial, también son útiles en el seguimiento de los pacientes para identificar erosiones articulares y permiten descartar otras patologías como artritis psoriásica, espondiloartropatías, gota o condrocalcinosis ${ }^{6}$.

\section{OBJETIVOS}

1. Identificar los hallazgos radiológicos comunes en artritis reumatoide.

2. Aprender el patrón de involucro articular característico en la enfermedad temprana y avanzada.
Tabla 1. Criterios de clasificación del Colegio Americano de Reumatología y la Liga Europea Contra el Reumatismo del 2010 para artritis reumatoide

\begin{tabular}{|c|c|}
\hline \multicolumn{2}{|c|}{$\begin{array}{l}\text { Población blanco, pacientes que tienen: } \\
\text { 1) Al menos una articulación con datos definitivos de } \\
\text { sinovitis (inflamación) } \\
\text { 2) Sinovitis que no se explica por otra enfermedad }\end{array}$} \\
\hline \multicolumn{2}{|c|}{$\begin{array}{l}\text { Los criterios de clasificación se dividen en categorías de la } \\
\qquad \text { A-D con un algoritmo basado en puntaje }\end{array}$} \\
\hline \multicolumn{2}{|c|}{ Un puntaje $\geq 6 / 10$ en necesario para un diagnóstico definitivo } \\
\hline Categoría & Puntaje \\
\hline $\begin{array}{l}\text { A. Involucro articular } \\
-1 \text { articulación grande* } \\
-2-10 \text { articulaciones grandes } \\
-4 \text { a } 10 \text { articulaciones pequeñas } \\
-\geq 10 \text { articulaciones (incluyendo al menos una pequeña) }\end{array}$ & $\begin{array}{l}0 \\
1 \\
3 \\
5\end{array}$ \\
\hline $\begin{array}{l}\text { B. Serología (al menos } 1 \text { resultado es necesario) } \\
\text { - FR y AAPC negativo } \\
\text { - FR o AAPC positivo leve } \\
\text { - FR o AAPC positivo alto }\end{array}$ & $\begin{array}{l}0 \\
2 \\
3\end{array}$ \\
\hline $\begin{array}{l}\text { C. Reactantes de fase aguda (al menos } 1 \text { resultado es } \\
\text { necesario) } \\
\text { - PCR normal y VSG normal } \\
\text { - PCR y VSG anormales }\end{array}$ & $\begin{array}{l}0 \\
1\end{array}$ \\
\hline $\begin{array}{l}\text { D. Duración } \\
-\leq 6 \text { semanas } \\
-\geq 6 \text { semanas }\end{array}$ & $\begin{array}{l}0 \\
1\end{array}$ \\
\hline \multicolumn{2}{|c|}{$\begin{array}{l}\text { *Hombros, codos, cadera, rodillas y tobillos. } \\
\text { †Articulaciones metacarpofalángicas, interfalángicas proximales, } 2 .^{\text {a }}-5{ }^{\text {a }} \\
\text { articulaciones metatarsofalángicas, interfalángica del primer dedo y muñeca. } \\
\text { AAPC: anticuerpos antipéptido citrulinado; FR: factor reumatoide; PCR: proteína } \\
\text { C reactiva; VSG: velocidad de sedimentación globular. }\end{array}$} \\
\hline
\end{tabular}

\section{MATERIAL Y MÉTODOS}

Revisión bibliográfica minuciosa y obtención de imágenes representativas en el archivo radiológico del Departamento de Radiología e Imagen del Instituto Nacional de Ciencias Médicas y Nutrición Salvador Zubirán.

Por motivos académicos, primero se abordarán las generalidades de la artritis reumatoide y posteriormente se revisarán los hallazgos imagenológicos específicos. 


\section{RESULTADOS}

\section{Hallazgos radiológicos comunes}

Los hallazgos en estudios de imagen se encuentran altamente relacionados con la clínica y los cambios fisiopatológicos subyacentes, como se muestra en la figura $2^{7}$. Cabe destacar que cuando se evalúa por imagen la $\mathrm{AR}$ se debe considerar que el tiempo de progresión y su involucro articular no es una relación lineal, en el mismo individuo puede haber diferentes hallazgos ${ }^{1,7}$. La evaluación radiológica debe basarse en el análisis individual y sistemático de los sitios más comúnmente afectados ${ }^{5,7}$. Primero se debe observar la distribución de las articulaciones comprometidas, y como fue discutido anteriormente, la AR muestra un daño poliarticular con involucro generalmente de forma bilateral y simétrica, especialmente en las articulaciones metacarpofalángicas, metatarsofalángicas e interfalángicas proximales ${ }^{5,7}$. Después se tienen que buscar los hallazgos imagenológicos más comunes, los cuales están resumidos en la figura 3, y serán discutidos a continuación:

- Inflamación de tejidos blandos (hiperemia y/o sinovitis). Es uno de los hallazgos más tempranos que se puede identificar por imagen. En las radiografías se puede apreciar como una discreta radiopacidad fusiforme periarticular que traduce sinovitis ${ }^{7}$. El ultrasonido y la RM son de utilidad en la evaluación de pacientes con cambios tempranos por $\mathrm{AR}$, además ambos métodos son más sensibles que la clínica para la evaluación de sinovitis asintomática y son de utilidad para distinguir poli de oligoartritis $^{8}$. El uso de ultrasonido Doppler poder permite identificar áreas con sinovitis que se traducen en la presencia de líquido articular con engrosamiento sinovial hipoecoico e incremento de la vascularidad ${ }^{9}$.

- Osteoporosis generalizada y periarticular. Es el signo radiológico en hueso más temprano detectado por radiografía y puede estar acompañado de signos de inflamación local. En pacientes con AR tiene una prevalencia del $26.5 \%$. Se debe a múltiples factores, entre ellos, el consumo prolongado de esteroides. Suele afectar el esqueleto axial y apendicular, y se incrementa el riesgo de fracturas en este grupo de pacientes ${ }^{5,10}$. La osteoporosis periarticular, también referida como osteopenia paraarticular o yuxtaarticular, refleja los cambios tróficos ocasionados por la alteración de la microcirculación y el desuso, provocando la activación de los osteoclastos cerca de las articulaciones ${ }^{1,10}$.

- Quistes subcondrales. Son pseudoquistes secundarios probablemente ocasionados por la extensión del pannus a través de la unión osteocondral, que permiten el paso de líquido y la formación de una cavidad. Se relacionan con la actividad física y sitios de presión. En articulaciones grandes suelen ser de mayor tamaño, por lo que aumentan el riesgo de fracturas subcondrales (cadera y rodilla). En las cabezas de los metacarpos se encuentran en el 2. ${ }^{\circ}, 3^{\circ}$ y 4 . $^{\circ}$ dedos en los sitios de inserción del ligamento colateral radial, y en la muñeca en el hueso grande en el sitio de inserción del ligamento radio-escafo-hueso grande ${ }^{1,5,11}$.

- Disminución del espacio articular. Es un indicador de enfermedad avanzada. Se debe a la destrucción progresiva del cartílago y la subsecuente formación de tejido fibroso que condiciona la disminución concéntrica del espacio articular ${ }^{1,11}$.

- Erosiones óseas. Es un reflejo de la destrucción cartilaginosa formando «áreas 


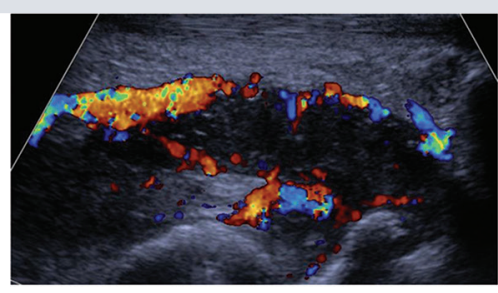

HIPEREMIA/SINOVITIS
OSTEOPOROSIS YUXTAARTICULAR

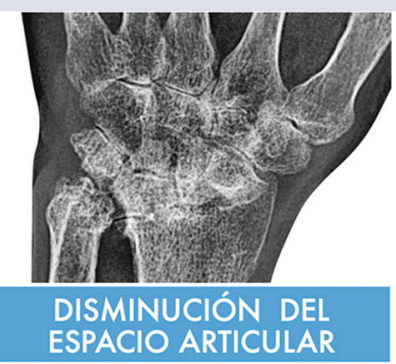

Edema
ESPACIO ARTICULAR

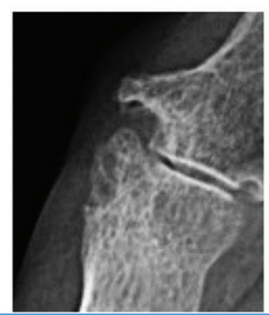

QUISTES SUBCORTICALES/ EROSIONES

Figura 2. Hallazgos radiológicos comunes. Las flechas verdes muestran los signos y síntomas de acuerdo con los cambios fisiopatológicos y su relación con los hallazgos radiológicos más frecuentes marcados en color azul.

desnudas» y comprometiendo el hueso subyacente. Se definen como pequeñas soluciones de continuidad cortical con exposición del hueso trabecular. Se desarrollan hasta en el $47 \%$ de los pacientes en el primer año del diagnóstico. En la práctica clínica son importantes porque pueden influenciar el tratamiento ${ }^{1,5,11}$.

- Hallazgos tardíos. Engloba todos los cambios relacionados con erosiones grandes, mutilación y destrucción de tejidos blandos periarticulares que condicionan subluxación/luxación y anquilosis. Las deformidades características y sus epónimos se resumen en la tabla $2^{1,5,7,12}$.

\section{Hallazgos radiológicos más comunes de «cabeza a pies»}

Columna cervical. La afección de la columna cervical está presente en el $86 \%$ de los pacientes con mayor predilección en aquellos que presentan enfermedad avanzada o tratamiento inadecuado $^{12}$. El sitio más comúnmente afectado es la articulación atlantoaxoidea. Se debe a la formación de pannus e infiltrado inflamatorio en la articulación C1-C2, lo cual ocasiona laxitud del complejo ligamentario y resulta en inestabilidad, predominantemente subluxación atlantoaxoidea anterior (SAA). Clínicamente se presenta con dolor (secundario a compresión de la raíz nerviosa de C2), aunque existen reportes de infarto cerebral y muerte súbita por insuficiencia vertebrobasilar ${ }^{10,12}$. La subluxación posterior es rara y ocurre generalmente cuando hay erosión o fractura de la base de la apófisis odontoides, además se asocia con mayor proporción a alteraciones neurológicas ${ }^{12}$. La inestabilidad puede progresar a la migración vertical de la odontoides hacia la bóveda craneal (invaginación basilar o impactación atlantoaxial $)^{13}$. Finalmente la AR también afecta los 

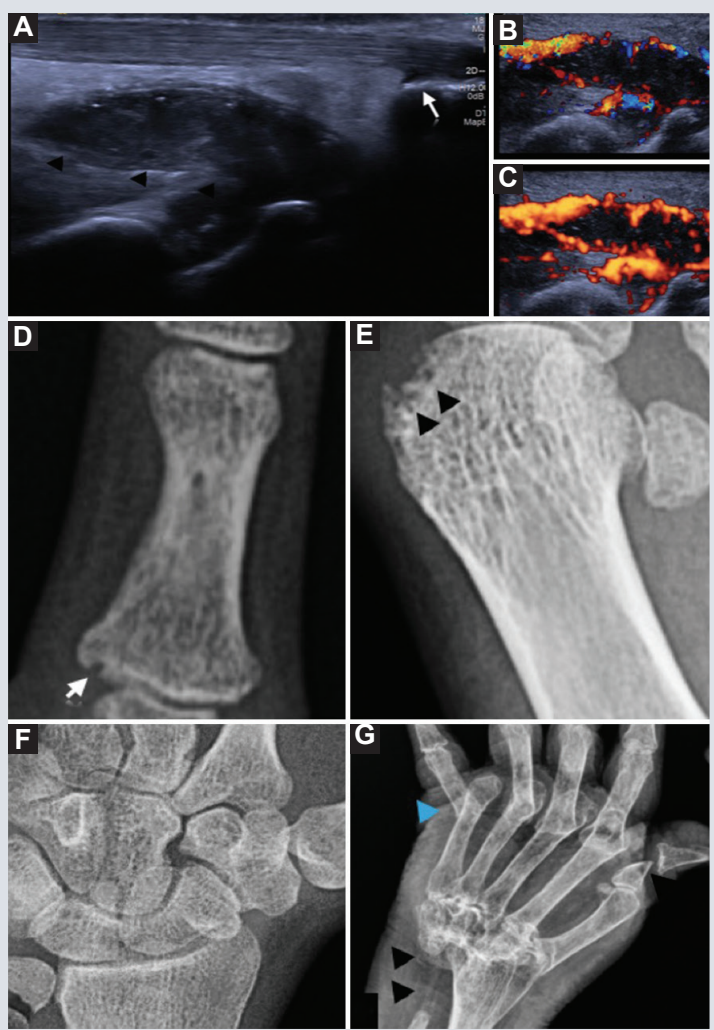

Figura 3. Hallazgos radiológicos comunes en manos y pies. A: hiperemia y sinovitis. Imagen de ultrasonido en la región posterior del tobillo izquierdo. Se observa escaso líquido en la inserción del tendón de Aquiles (flecha blanca). Inferior al mismo se observa una imagen ovalada de ecotextura heterogénea predominantemente hipoecoica en relación con sinovitis en el aspecto posterior de la articulación tibioastragalina, hallazgo común en esta región (cabezas de flecha). B-C: a la aplicación de Doppler color y poder, respectivamente, presenta vascularidad incrementada (hiperemia). D: quiste subcondral. Imagen magnificada de la articulación interfalángica proximal del $4 .^{\circ}$ dedo de la mano izquierda. La flecha señala una imagen compatible con quiste subcondral. E: erosiones. Magnificación obtenida de una radiografía del pie izquierdo, donde se observan múltiples soluciones de continuidad cortical en la cabeza del metatarso del primer dedo (cabezas de flecha) en relación con erosiones óseas. Nótese su disposición periarticular en el área desnuda del hueso. F: radiografía AP de la mano derecha, donde se observa una discreta disminución del espacio articular de predominio radiocarpal. G: hallazgos tardíos. Radiografía de la mano derecha. Las cabezas de flecha negras demuestran osteólisis de la cabeza del cúbito y de la falange proximal del primer dedo. Nótese la anquilosis en los huesos del carpo y la luxación de la 5. articulación metacarpofalángica (cabeza de flecha azul).

AP: anteposterior.
TABLA 2. Hallazgos tardíos y sus epónimos

\begin{tabular}{|l|l|}
\hline Epónimo & Hallazgos \\
\hline $\begin{array}{l}\text { Dedo de } \\
\text { Mallet (en } \\
\text { martillo) }\end{array}$ & $\begin{array}{l}\text { Falange distal en flexión, condicionada por } \\
\text { incremento en la laxitud o disrupción de la } \\
\text { inserción del tendón extensor de la falange distal }\end{array}$ \\
\hline $\begin{array}{l}\text { Deformidad en } \\
\text { cuello de cisne }\end{array}$ & $\begin{array}{l}\text { Flexión de la articulación IFD e hiperextensión } \\
\text { de la articulación IFP }\end{array}$ \\
\hline $\begin{array}{l}\text { Deformidad de } \\
\text { Boutonnière }\end{array}$ & $\begin{array}{l}\text { Hiperextensión de la articulación IFD y flexión } \\
\text { de la articulación IFP }\end{array}$ \\
\hline $\begin{array}{l}\text { Deformidad } \\
\text { de Hitchhiker }\end{array}$ & $\begin{array}{l}\text { Hiperextensión de la articulación IFD y flexión } \\
\text { de la articulación MCF proximal }\end{array}$ \\
\hline
\end{tabular}

IFD: interfalángica distal; IFP: interfalángica proximal; MCF: metacarpofalángica.

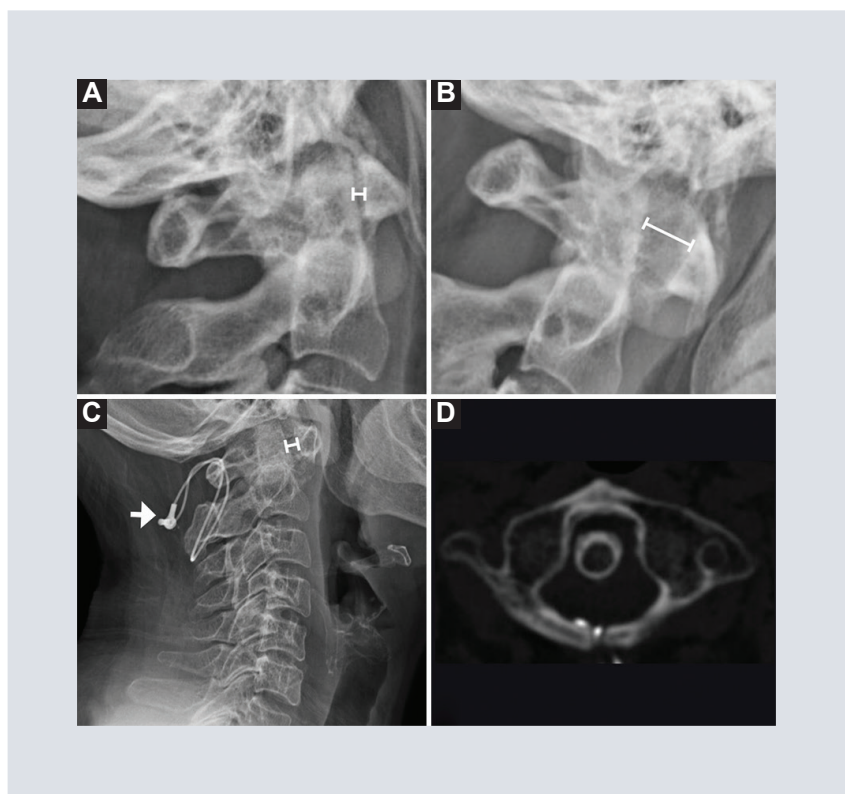

Figura 4. Hallazgos en la columna cervical. A: vista magnificada de proyección lateral de una radiografía de la columna cervical en reposo en un paciente con artritis reumatoide. B: el espacio atlantoodontoideo (marcado por el conector blanco) es de $3 \mathrm{~mm}$ en reposo (normal $<3 \mathrm{~mm}$ ) e incrementa a $7 \mathrm{~mm}$ en flexión en la vista magnificada en relación con subluxación atlantoaxoidea. C: proyección lateral de una radiografía de columna cervical obtenida en reposo en la que se observa el material de cerclaje posterior (flecha blanca) e incremento del espacio atlantoodontoideo. D: en el mismo paciente una tomografía en corte axial obtenido a nivel de C1-C2 en ventana para hueso, donde además se visualiza desplazamiento lateral del atlas sobre el axis. La tomografía es de gran utilidad para valorar el desplazamiento lateral, además de descartar fractura de la odontoides. 


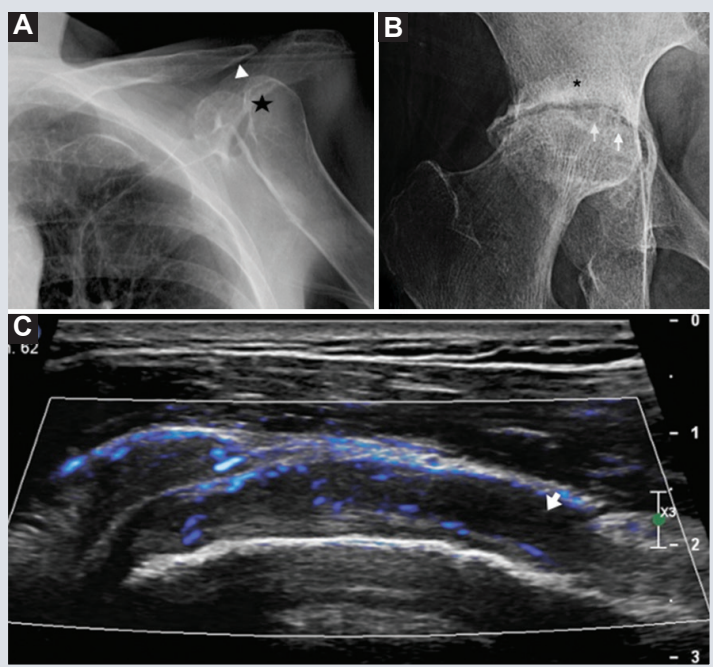

Figura 5. Hallazgos comunes en hombros y pelvis.

A: radiografía anteroposterior del hombro izquierdo en abducción. Nótese la osteólisis del tercio distal de la clavícula (cabeza de flecha blanca), además del desplazamiento superior de la cabeza femoral.

B: magnificación de radiografía anteroposterior de la pelvis derecha, donde se observa pérdida de la morfología de la cabeza femoral por colapso del hueso subcondral (flechas) asociado a disminución del espacio articular con esclerosis subcondral $(*)$, compatible con grado $\mathrm{V}$ en la clasificación de Ficat y Arlet. C: vista sagital del tendón largo de la cabeza del bíceps derecho en un paciente con artritis reumatoide y dolor en este sitio. Se visualizó líquido adyacente a su trayecto (flecha gruesa) e incremento de la vascularidad a la aplicación de microflow ( $\mathrm{MCl}$, por sus siglas en inglés), que traducen tenosinovitis.

segmentos de C3 a C7 con subluxaciones multinivel con deformidad en escalera en casos avanzados, lo que condiciona radiculopatía por estenosis del canal cervical ${ }^{12,13}$. Las radiografías de la columna cervical incluyen proyecciones anteroposterior, lateral, oblicuas, en flexión y extensión, con boca abierta para la visualización de la odontoides (Fig. 4). En caso de encontrar anormalidades en las radiografías o ante la presencia de síntomas neurológicos importantes se pueden indicar la tomografía computarizada (TC) y/o resonancia magnética para valoración prequirúrgica ${ }^{10,13}$.

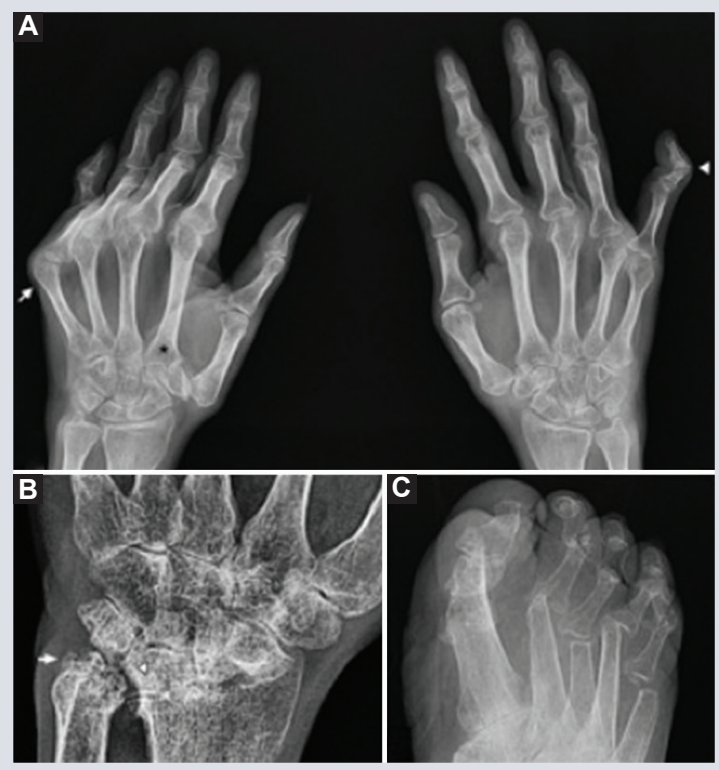

Figura 6. Cambios avanzados de artritis reumatoide (AR) en manos y pies. A: radiografía anteroposterior bilateral de una mano en posición neutra en un paciente con AR. Nótese la importante osteopenia yuxtaarticular (marcada con *) en ambas manos, además de la disminución del espacio articular de predominio en articulaciones metacarpofalángicas e interfalángicas proximales. En el quinto dedo de la mano izquierda se observa deformidad en cuello de cisne (cabeza de flecha); además, en la mano derecha existe desviación cubital de los metacarpos con subluxación palmar de las articulaciones metacarpofalángicas. B: magnificación de una radiografía de muñeca $A P$, donde se observa erosr del pie izquierdo en un paciente con enfermedad avanzada donde se observa osteólisis de la cabeza de los metatarsianos. AP: anteroposterior. C: radiografía de pie izquierdo en un paciente con enfermedad avanzada donde se observa osteólisis de la cabeza de los metatarsianos.

Hombros y codo. En los hombros, las áreas más afectadas son la articulación glenohumeral, el manguito rotador y el tercio distal de la clavícula. La osteolisis del tercio distal de la clavícula y erosiones en la inserción del ligamento coracoclavicular son hallazgos comunes. El manguito rotador presenta roturas crónicas y desplazamiento superior de la cabeza femoral, lo que ocasiona cambios en la biomecánica del hombro y erosiones (Fig. 5) 5,14. 
En el codo, las erosiones en la articulación húmero-radial y húmero-cubital preceden a la pérdida del espacio articular. También puede observarse derrame articular y bursitis del olécranon ${ }^{5,14}$.

Mano y muñeca. El espectro de cambios radiográficos va desde anormalidades sutiles a cambios destructivos graves (Fig. 6). Dependiendo del grado de afección, la articulación puede presentar disminución del grosor del cartílago articular, erosiones óseas, subluxación, anquilosis y cambios por mutilación ${ }^{6,14}$. La muñeca y las articulaciones metacarpofalángicas son las primeras articulaciones afectadas ${ }^{1,5,9,14}$. La extremidad dominante tiende a ser la que presenta mayor daño. La tenosinovitis es el hallazgo más común y afecta predominantemente el extensor y flexor de los dedos, y el extensor cubital del carpo ${ }^{5,9,14}$. En cuanto a las erosiones óseas, suelen ser unilaterales y afectar el hueso escafoides, piramidal, semilunar y el aspecto lateral del quinto metacarpo 9,14. Además, la sinovitis crónica de las articulaciones metacarpofalángicas conduce a inestabilidad con desviación cubital y subluxación palmar. Las deformidades características asociadas a estadios avanzados fueron discutidas previamente y resumidas en la tabla 2 . Las radiografías de mano y muñeca incluyen proyecciones posteroanterior, lateral de muñecas y/o vista de Norgaard (anteroposterior semisupinada). Esta última es útil para valorar la presencia de cambios erosivos en el hueso pisiforme, aspecto palmar del semilunar y de la superficie cubital del ganchoso $0^{5,14}$.

Pelvis y rodilla. En la pelvis la afección del cartílago se traduce en disminución simétrica, concéntrica y bilateral de las articulaciones coxofemorales, con migración axial de la cabeza
Tabla 3. Clasificación de Ficat y Arlet para necrosis avascular

\begin{tabular}{|l|l|l|}
\hline Estadio & Clínica & Hallazgos radiológicos \\
\hline I & $\begin{array}{l}\text { Sin } \\
\text { dolor }\end{array}$ & $\begin{array}{l}\text { Normal. Cambios en la captación en } \\
\text { gammagrama óseo }\end{array}$ \\
\hline II & $\begin{array}{l}\text { Dolor } \\
\text { variable }\end{array}$ & $\begin{array}{l}\text { Cambios en el hueso trabecular con } \\
\text { quistes y zonas de esclerosis focal. La } \\
\text { cabeza femoral preserva su forma }\end{array}$ \\
\hline III & Dolor & $\begin{array}{l}\text { Colapso del hueso subcondral (signo del } \\
\text { halo creciente) }\end{array}$ \\
\hline IV & $\begin{array}{l}\text { Colapso marcado del hueso subcondral con } \\
\text { espacio articular coxofemoral preservado. }\end{array}$ \\
\hline V & & Lo anterior + osteoartritis secundaria \\
\hline
\end{tabular}

femoral y deformidad acetabular (protrusio acetabuli secundaria) $)^{5,14}$. Otro hallazgo común es la osteonecrosis $(\mathrm{ON})$ o necrosis avascular de la cabeza femoral, favorecida por el uso crónico de esteroides en estos pacientes. La fisiopatología en la $\mathrm{ON}$ inducida por estos fármacos es incierta, sin embargo, existe una relación directa entre su uso prolongado y el riesgo de presentarla. La evaluación inicial es por radiografía y en la mayoría de los pacientes suele ser asintomática. La TC y particularmente la RM son más sensibles para detectarla, sin embargo, no se usan de forma habitual. Existen clasificaciones para evaluar la progresión radiológica, la más utilizada en adultos es la escala de FicatArlet-Steinberg (Tabla 3) $)^{11,14}$. La rodilla es la articulación grande que más frecuentemente se afecta. El derrame articular y el quiste sinovial en la región poplítea son los signos más tempranos. Algo característico es la afección tricompartimental de la rodilla que refleja la destrucción uniforme del cartílago (Fig. 5) 5,7,14.

Tobillo y pies. Siendo la AR una enfermedad poliarticular, hasta el $90 \%$ de los pacientes presentan afección de tobillo y pies. Como en otras articulaciones, la inflamación de tejidos 
TABla 4. Características de evaluación de las escalas radiográficas para severidad en artritis reumatoide

\begin{tabular}{|c|c|c|c|c|c|c|c|}
\hline Escala & DEA & Erosiones & Osteopenia & ITB & Subluxación & Anquilosis & Quistes \\
\hline Sharp (1985) & $\mathrm{x}$ & $x$ & & & & $x$ & $x$ \\
\hline Van der Heijde/Sharp (1989) & $\mathrm{x}$ & $x$ & & & $x$ & $x$ & \\
\hline Genant (1998) & $x$ & $x$ & & & $x$ & $x$ & \\
\hline Scott/Larsen (1995) & $x$ & $\mathrm{x}$ & $\mathrm{x}$ & $\mathrm{x}$ & $\mathrm{x}$ & & $\mathrm{x}$ \\
\hline SENS (1999) & $\mathrm{x}$ & $x$ & & & $x$ & $x$ & \\
\hline SES (2000) & $x$ & $x$ & & & & & \\
\hline
\end{tabular}

DEA: disminución del espacio articular; ITB: inflamación de tejidos blandos. Adaptado de Boini S, et al. ${ }^{15}$

blandos y la osteopenia yuxtaarticular son signos tempranos de la enfermedad. Además, debido a la degeneración y laxitud ligamentaria, la biomecánica de estas articulaciones se encuentra alterada; por ejemplo, en las estructuras plantares, la degeneración del ligamento transverso ocasiona la disminución y ensanchamiento del arco plantar ${ }^{5,14}$. Las articulaciones más afectadas son las metatarsofalángicas, de predominio en su aspecto lateral y en la cabeza de los metatarsos. La proliferación sinovial en el tobillo se puede traducir en afección de las articulaciones subastragalinas como masa palpable superior al cuello del astrágalo o afectando la región posterior como bursitis retrocalcánea, e incluso pueden presentarse erosiones del aspecto posterior del calcáneo. De igual forma se pueden presentar cambios por enfermedad avanzada como en la muñeca y manos (anquilosis, subluxación, etc. $)^{5,14}$.

El conocer estos hallazgos mejora la evaluación de los pacientes y en su seguimiento por imagen permite establecer la efectividad de la respuesta al tratamiento. Existen varias escalas que valoran de forma objetiva el grado de afección por radiografía, la mayoría evalúa la disminución del espacio articular y la presencia de erosiones principalmente en manos y pies (Tabla 4). Sin embargo, ningún sistema de clasificación ha sido aceptado para su uso general y son mayormente utilizados para propósitos de investigación ${ }^{1,15}$.

\section{CONCLUSIONES}

La artritis reumatoide es una enfermedad sistémica, crónica e inflamatoria que afecta principalmente las articulaciones sinoviales. El diagnóstico requiere de una serie de criterios dentro de los cuales se encuentra el radiológico. Si bien el ultrasonido y la RM permiten mejor valoración de los tejidos blandos, el enfoque radiológico inicial en un caso sospechoso de artritis es frecuentemente el uso de la radiografía convencional.

Los hallazgos por imagen y el patrón característico de involucro articular pueden hacer el diagnóstico con alta precisión, por lo que es importante que el radiólogo tenga amplios conocimientos de ellos y así orientar al médico tratante. Como ya se revisó en este artículo, el proceso inflamatorio articular y la destrucción 
del cartílago es un fenómeno progresivo, así que cobra importancia la detección temprana de anomalías radiológicas que permitan a los médicos iniciar el tratamiento inmediato con un régimen terapéutico adecuado antes de que se produzcan cambios destructivos que empeoren el pronóstico del paciente.

\section{AGRADECIMIENTOS}

Los autores agradecen a Carlos Casian Ruiz Velasco por sus ilustraciones.

\section{CONFLICTO DE INTERESES}

Los autores declaran que no tienen conflicto de intereses que declarar.

\section{RESPONSABILIDADES ÉTICAS}

Protección de personas y animales. Los autores declaran que para esta investigación no se han realizado experimentos en seres humanos ni en animales.

Confidencialidad de los datos. Los autores declaran que en este artículo no aparecen datos de pacientes.
Derecho a la privacidad y consentimiento informado. Los autores declaran que en este artículo no aparecen datos de pacientes.

\section{BIBLIOGRAFÍA}

1. Sommer OJ, Kladosek A, Weiler V, Czembirek H, Boeck M, Stiskal M. Rheumatoid arthritis: a practical guide to state-of-the-art imaging, image interpretation, and clinical implications. Radiographics. 2005 MarApr;25(2):381-98.

2. Gabriel SE. The epidemiology of rheumatoid arthritis. Rheum Dis Clin North Am. 2001;27:269-82.

3. Lee DM, Weinblatt ME. Rheumatoid arthritis. Lancet. 2001;358(9285):903.

4. Aletaha D, Neogi T, Silman AJ, Funovits J, Felson DT, Bingham CO, et al. 2010 Rheumatoid arthritis classification criteria: an American College of Rheumatology/European League Against Rheumatism collaborative initiative. Arthritis Rheum. 2010;62(9):2569-81.

5. Llopis E, Kroon HM, Acosta J, Bloem JL. Conventional Radiology in Rheumatoid Arthritis. Radiol Clin North Am. 2017;55(5):917-941.

6. Aletaha D, Smolen JS. Diagnosis and Management of Rheumatoid Arthritis: A Review. JAMA. 2018;320(13):1360-72.

7. Jacobson JA, Girish G, Jiang Y, Resnick D. Radiographic evaluation of arthritis: inflammatory conditions. Radiology. 2008;248(2):378-89.

8. Narvaez JA, Narvaez J, Roca Y, Aguilera C. MR imaging assessment of clinical problems in rheumatoid arthritis. Eur Radiol. 2002; 12:1819-28.

9. Boutry N, Morel M, Flipo RM, Demondion X, Cotten A. Early rheumatoid arthritis: a review of MRI and sonographic findings. AJR Am J Roentgenol. 2007;189(6):1502-9.

10. Joaquim AF, Ghizoni E, Tedeschi H, Appenzeller S, Riew KD. Radiological evaluation of cervical spine involvement in rheumatoid arthritis. Neurosurg Focus. 2015;38(4): E4.

11. Murphey MD, Foreman KL, Klassen-Fischer MK, Fox MG, Chung EM, Kransdorf MJ. From the radiologic pathology archives imaging of osteonecrosis: radiologic-pathologic correlation. Radiographics. 2014;34(4):1003-28.

12. Krauss WE, Bledsoe JM, Clarke MJ, Nottmeier EW, Pichelmann MA. Rheumatoid arthritis of the craniovertebral junction. Neurosurgery. 2010;66(3 Suppl):83-95.

13. Joaquim AF, Appenzeller S: Cervical spine involvement in rheumatoid arthritis-a systematic review. Autoimmun Rev. 2014;13:1195-202.

14. Kieft GJ, Dijkmans BAC, Bloem JL, et al. Magnetic resonance imaging of the shoulder in patients with rheumatoid arthritis. Ann Rheum Dis. 1990;49:7-11.

15. Boini S, Guillemin F. Radiographic scoring methods as outcome measures in rheumatoid arthritis: properties and advantages. Ann Rheum Dis. 2001;60(9):817-27. 